\title{
Knowledge transfer in university-industry research partnerships: a review
}

\author{
Esther de Wit-de Vries ${ }^{1}\left(\mathbb{D} \cdot\right.$ Wilfred A. Dolfsma $^{2}$ (D) Henny J. van der Windt ${ }^{1}$. \\ M. P. Gerkema ${ }^{1}$
}

\begin{abstract}
This paper identifies practices that can facilitate knowledge transfer in university-industry (U-I) research partnerships by systematically reviewing extant literature. We aim to contribute to the theoretical development in the field of academic engagement and propose that knowledge transfer provides a valuable perspective. We started our review with identifying barriers and facilitators of knowledge transfer. Extant literature identified knowledge differences and differences in goals resulting from different institutional cultures as important barriers to knowledge transfer. They result in ambiguity, problems with knowledge absorption and difficulties with the application of knowledge. Trust, communication, the use of intermediaries and experience are found as facilitators for knowledge transfer that help to resolve the identified barriers. Our analysis offers practical advice for the management of academic engagement. Finally, we identified questions for future research based on inconsistencies in extant research and open questions we encountered during our analysis.
\end{abstract}

Keywords Research collaboration - Academic partnerships · University-Industry · University-Business $\cdot$ Knowledge transfer $\cdot$ Knowledge management $\cdot$ Practices $\cdot$ Barriers $\cdot$ Facilitators $\cdot$ Ambiguity $\cdot$ Absorptive capacity $\cdot$ Cultural differences $\cdot$ Goals $\cdot$ Trust

JEL Classification $\quad \mathrm{D} 2 \cdot \mathrm{D} 8 \cdot \mathrm{D} 9 \cdot \mathrm{L} 2$

Henny J. van der Windt

H.J.van.der.Windt@rug.nl

1 Science and Society Group, Faculty of Science and Engineering, University of Groningen, Groningen, The Netherlands

2 Glendonbrook Institute for Enterprise Development, Loughborough University London, London, UK 


\section{Introduction}

\subsection{Knowledge transfer practices in U-I collaborations}

Knowledge transfer between academia and industry is considered an important driver of innovation and economic growth as it eases the commercialization of new scientific knowledge within firms (Bercovitz and Feldmann 2006; Mowery and Nelson 2004). Researchers benefit from the interaction with industry as well, as it can inspire new research directions and provides additional funding (D'Este and Perkmann 2011). Over the past decades, research into academic engagement increased. Most of this research studied academic entrepreneurship (Agrawal 2001; Shane 2005), which includes patenting, licensing, joint ventures, spin-offs and so forth. However, there are other ways for academics to ensure application of their knowledge these practices focus predominantly on knowledge exchange (Salter and Martin 2001; Alexander and Childe 2013). These forms of interaction have been referred to as academic engagement or academic partnership (Perkmann et al. 2013). In this paper we focus on these kinds of academic engagement which we define as research partnerships based on "high relational involvement in situations where individuals and teams from academic and industrial contexts work together on specific projects and produce common outputs" (Perkmann and Walsh 2007, p. 263). This means that we will focus on research partnerships, collaborative research, contract research and consulting while collaborations with limited interaction or that require little or no new research are excluded.

Although university income from academic engagement outranks income derived from selling intellectual property (IP) (Perkmann et al. 2011) and is valued higher by industry (Cohen 2002), researchers into university-industry interactions have ignored these forms of collaborations for a long time. Since 2006 research into academic engagement is increasing (Perkmann et al. 2013). Up till now, the field is still behind in the development of theoretical perspectives. We propose that research into academic engagement can build on theory on knowledge transfer to fill this gap. Academic engagement, after all, aims to develop novel knowledge that benefits the academic and industrial partner. This requires bidirectional knowledge sharing to identify relevant problems, share and develop new insights, and the transfer and implementation of knowledge or technology.

In this paper we aim to map extant knowledge and perspectives on knowledge transfer in academic engagement through a systematic literature review. Additionally, we identify open questions for future research. Besides our aim to develop a theoretical perspective to study academic engagement our focus on knowledge transfer adds to previous reviews on academic engagement. As those have focussed on characteristics of researchers and institutions (Perkmann et al. 2013), factors that affect collaboration but did not focus on academic engagement, its management or knowledge transfer (Ankrah and AL-Tabbaa 2015; Agrawal 2001), tried to define academic engagement (Perkmann and Walsh 2007) or discussed policies (Hagedoorn 2002; Hagedoorn et al. 2000).

In this review we discuss which theoretical frames could deepen our understanding of university-industry (U-I) knowledge transfer, identify barriers and facilitators of knowledge transfer and use a 'practices perspective' to identify ways to deal with these barriers. This allows us to emphasize social interactions, managerial aspects and concrete activities that enhance knowledge transfer. The term "practice" can refer to a broad range of activities. We use the term to refer to institutionalized daily events at a workplace (Nicolini 2009). The abstraction level we use is such that it can be translated into managerial implications. In adopting this focus we follow a developing interest in organization science that 
seeks a detailed understanding of "what is actually done', or "the micro-level", and how to make sense of those activities (Nicolini 2009).

To define knowledge transfer we used the definition by Bloedon and Stokes (1994, p. 44) who defined this as 'the process by which knowledge concerning the making or doing of useful things contained within one organized setting is brought into use within another organizational context'. Knowledge transfer practices are then defined as the activities that facilitate what is needed to bring knowledge into use in another organization's context, such as, teaching, the management of interactions and sharing data and technology.

This paper continues with a methodological section that describes our review process. The third section outlines our analysis of the literature resulting from our review. In that section we provide an overview of theoretical perspectives and activities that have been described in previous research. We aim to realize generalization and accumulation of knowledge and to identify issues which are inconclusive or have been ignored in the extant literature and provide practices that facilitate the management of academic engagement in practice. The paper concludes with translating these insights into an analytical framework and research agenda.

\subsection{Methodology}

Following previous research in the field of U-I research (for example Perkmann et al. (2013) and Ankrah and AL-Tabbaa (2015) we used the principles and process of a systematic literature review (Tranfield et al. 2003). While conducting our review we encountered some problems in our search process. The main problem was that there is little consistency in the terminology used to describe research partnerships/academic engagement and knowledge transfer. Secondly, the literature that focusses on knowledge transfer and management of such collaborations is scarce. As a result, combining key words such as academic engagement or research partnerships with knowledge transfer or knowledge management provided limited results. We developed a methodology that overall followed the analytical process of a systematic review but differs from other systematic reviews when it comes to searching and identifying relevant literature. Therefore, the following section describes our method in detail.

\subsection{Scope}

Previous reviews by Agrawal (2001), Hagedoorn et al. (2000) and Hagedoorn (2002) concluded that there was a lack of research into transfer channels other than commercialization. Also Perkmann et al. (2013) found that literature on academic engagement was mainly published after 2006. Therefore, we did not expect to find many papers on knowledge transfer before 2002 and selected the period 2002-2016 for our review. We also searched the period 1997-2001 to verify the findings by Perkmann et al. (2013), but we did not find relevant papers in this period. We only searched within English peer reviewed journal articles. Instead of limiting our search to a list of prominent journals we decided to include a wide range of economic and managerial literature. This was necessary as literature on research partnerships is widespread. We used the following academic databases: Emerald, Web of Knowledge and Business Source Premier. In the end we identified relevant papers in 26 different journals. There were only six journals in which we found more than 1 paper, three of those had published two papers and three published three papers. 


\subsection{Search protocol}

The initial search strategy was to find papers discussing "research partnership*", "academic engagement" or papers that combined "scienc*, academi* or university" with "industry* or business", in combination with "knowledge management", "knowledge transfer" or "technology transfer". This, however, did not provide many useful results. Therefore, we changed the search strategy to an approach in which we used broad Boolean search strings to identify papers on academic engagement from which we manually selected the ones that discuss research partnerships in relation to knowledge transfer. We searched in: titles, keywords and abstracts using the terms: 'University-business', 'university-industry' "academic engagement" and "research partnership" (other terms for university such as 'Academ*' and 'Higher Education' 'science' did not yield additional results), combined with one of the terms 'collaborat*', 'cooperation*', 'partnership*', 'engage*', 'relation* 'research' 'alliance*'. The term 'research' generated results for a broad range of terms used to indicate collaborations such as joint research, collaborative research, contract research and so on. Our search terms were based on previous reviews by Ankrah and AL-Tabbaa (2015) and Perkmann et al. (2013). The results from the Boolean search from the three literature databases were combined in Rayyan (Ouzzani et al. 2016). In total we found about 890 unique papers.

From these results we selected papers that could help us answer the following research questions: What is known about knowledge transfer in academic engagement according to the extant literature. How can failure and success of knowledge transfer be explained? And what practices facilitate the transfer of knowledge in academic engagement? We used the following steps and criteria (see Fig. 1). First, we excluded papers that focus solely on entrepreneurial activities like patenting, liaison offices, science-hubs and other intermediary organisations. Second, we excluded papers that were not related to knowledge transfer. Third, we only included papers that gave theoretical explanations relating to effectiveness of knowledge transfer, papers that identified factors that influence knowledge transfer and papers that describe knowledge transfer practices and management practices that influence

Fig. 1 Selection criteria

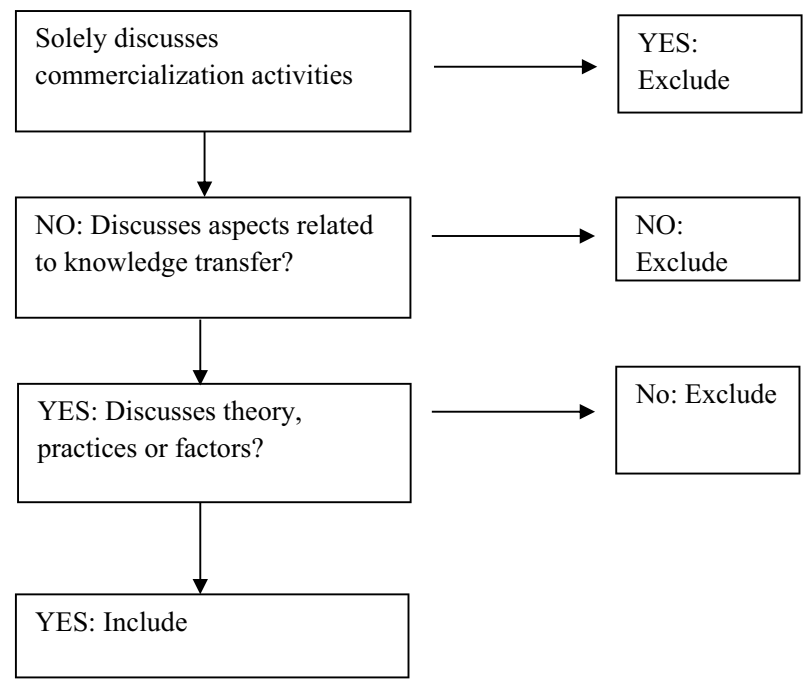


knowledge transfer. If the abstract was unclear about the content, the decision to include a paper was made after scanning the whole paper.

There are not many papers that focus explicitly on knowledge transfer in academic engagement (Bruneel et al. 2010). To find literature that discusses knowledge transfer we first identified the factors that affect knowledge transfer in inter-organizational collaboration. This can be justified when we follow the logic that academic engagement is a specific form of inter-organizational collaboration or alliance (see for example Galan-Muros and Plewa 2016). Additionally, we looked for research that confirmed the relevance of the factors we identified for academic engagement. To identify the inter-organizational factors we used a paper by Van Wijk et al. (2008). This study combined results from 75 papers on knowledge transfer to re-evaluate previous quantitative findings from inter- and intraorganizational studies. We only used the factors that were relevant for inter-organizational collaborations, absorptive capacity, ambiguity, cultural differences, differences in goals, trust and tie-strength (Fig. 2).

These factors and their definitions (see below) were used to decide which of the papers on academic engagement in our results discussed topics that could be related to knowledge transfer. Van Wijk et al. (2008) identified "absorptive capacity" and "ambiguity" as important factors. Given that these factors relate to differences in knowledge background and the complexity of knowledge we included all research that discussed differences in knowledge background and knowledge characteristics. "Cultural differences" and "differences in goals" were also identified by van Wijk et al. (2008) and literature that discussed such differences was therefore included. "Trust" and "tie-strength" were identified as important facilitators. We therefore included literature that discussed these factors, but also other forms of relational capital. We found 35 papers that discussed relevant insights into knowledge transfer after applying the inclusion and exclusion criteria (for an overview of the papers see Table 1).

\subsection{Data analysis process}

The next step was to analyse the papers we selected. First, we prepared a table which summarized the research questions and answers. Second, we identified the information that related to knowledge transfer and included this in our table. Third, we organized our literature in line with three themes-cognitive difference, institutional differences and social capital in a summarizing document that formed the basis for the analysis.

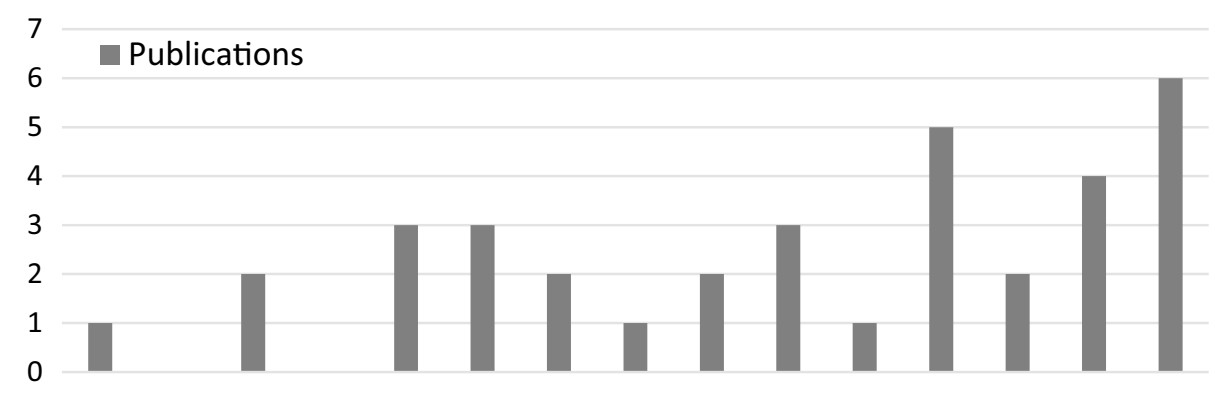

200220032004200520062007200820092010201120122013201420152016

Fig. 2 Publications per year 
Table 1 Selected papers sorted by topic

\begin{tabular}{|c|c|}
\hline Topic & Core publications \\
\hline Cognitive differences & $\begin{array}{l}\text { Alexander and Childe (2013), Al-Tabbaa and Ankrah (2016), Azevedo Ferreira } \\
\text { and Rezende Ramos (2015), Barnes et al. (2002), Buganza et al. (2014), Can- } \\
\text { hoto et al. (2016), Corley et al. (2006), Daghfous (2004), D'Este and Perkmann } \\
\text { (2011), Gertner et al. (2011), Hadjimanolis (2006), Galan-Muros and Plewa } \\
\text { (2016), Harryson et al. (2007), Johnson and Johnston (2004), McCabe et al. } \\
\text { (2016), Mesny and Mailhot (2007), Perkmann et al. (2011), Sandberg et al. } \\
\text { (2015), Santoro and Bierly (2006), Steinmo (2015), Ulhøi et al. (2012), Wallin } \\
\text { et al. (2014) and Wang and Lu (2007) }\end{array}$ \\
\hline Differences in goals & $\begin{array}{l}\text { Al-Tabbaa and Ankrah (2016), Azevedo Ferreira and Rezende Ramos (2015), } \\
\text { Barnes et al. (2002), Canhoto et al. (2016), Estrada et al. (2016), Ghauri and } \\
\text { Rosendo-Rios (2016), Mesny and Mailhot (2007), McCabe et al. (2016), Mesny } \\
\text { and Morandi (2010), Muscio and Pozzali (2013), Plewa et al. (2013a), Steinmo } \\
\text { (2015, 2013), Wallin et al. (2014) and Zhu and Hawk (2015) }\end{array}$ \\
\hline Social capital & $\begin{array}{l}\text { Barnes et al. (2002), Bruneel et al. (2010), Buganza et al. (2014), Canhoto et al. } \\
\text { (2016), Chin et al. (2011), Philbin (2008), Pinheiro et al. (2015), Plewa et al. } \\
\text { (2013a, b), Sandberg et al. (2015), Sherwood and Covin (2008), Steinmo (2015) } \\
\text { and Ulhøi et al. (2012) }\end{array}$ \\
\hline
\end{tabular}

\section{Factors influencing knowledge transfer}

Before turning to the analysis of the selected papers we will discuss the definitions of and relations between the factors identified by Van Wijk et al. (2008) and relate them to literature on academic engagement. The factors relating to cognitive differences are ambiguity and absorptive capacity. They relate to differences in knowledge background between the firm and the academics. Similarity in knowledge backgrounds makes it easier to understand and absorb new knowledge that results from the collaboration. Knowledge ambiguity refers to a situation where dissimilarities in knowledge result in "inherent and irreducible uncertainty regarding what the underlying knowledge components and sources are precisely, and how they interact" (van Wijk et al. 2008). It is an aggregated term for various knowledge characteristics of which the tacit nature (Polanyi 1966), complexity and the limited possibilities for specification (Simonin 1999) are the most important. Knowledge that has these characteristics is hard to identify, understand and transfer (ibid.). Hence, ambiguity is negatively related to knowledge transfer and hard to resolve without on the job training (Van Wijk et al. 2008).

Absorptive capacity refers to the ability to recognize, assimilate and apply new external knowledge (Cohen and Levinthal 1990). The capability of firms to absorb new knowledge depends on the shared knowledge base of the academics and the firm employees. It has a strong relationship with causal ambiguity, as it also strongly depends on a shared knowledge base (Cohen and Levinthal 1990).

The relevance of ambiguity and absorptive capacity in the context of U-I collaboration was confirmed by Santoro and Bierly (2006). They showed that technological relatedness and technological capability (which increases absorptive capacity) were the most important facilitators of knowledge transfer in U-I collaborations. In the same study, tacitness and explicitness (related to knowledge ambiguity) moderated knowledge transfer negatively.

Institutional factors are cultural differences and shared goals. The term cultural differences is used to indicate a lack of shared meaning and social conventions (Tsai and Ghoshal 1998). This complicates collaboration because different languages, opinions, social 
behaviours, norms and beliefs make the interpretation of behaviour and knowledge more difficult (Lane and Lubatkin 1998; Mowery and Shane 2002; Simonin 1999).

Different goals relate to the different ways in which business and academia benefit from knowledge. Shared goals are needed to reach a common understanding of the desired output and the interpretation of results (Tsai and Ghoshal 1998). When shared goals are lacking it becomes more difficult to understand the implications and cause effect relations of the knowledge developed, which causes ambiguity (Partha and David 1994). Different goals are also seen as an obstacle to build trust (Davenport et al. 1998). The relevance of cultural differences for U-I collaborations is confirmed by research from Bruneel et al. (2010), Cyert and Goodman (1997), Liyanage and Mitchell (1994), Partha and David (1994), Galan-Muros and Plewa (2016) and Ghauri and Rosendo-Rios (2016).

Social capital in the form of tie strength and trust reflects the closeness of a relationship and positively influences knowledge transfer (Bloedon and Stokes 1994; Bruneel et al. 2010; Davenport et al. 1998; Santoro and Gopalakrishnan 2001). Tie strength is a measure for the frequency of interactions and communication. While trust is used to express the reliability of a partner (Hansen 1999). Tie strength influences trust positively. Additionally, trust and tie strength are associated with the commitment to help a partner to understand new knowledge (Hansen 1999; Inkpen 2000). Sherwood and Covin (2008) found that trust is positively associated with tacit knowledge transfer, as trust increases open communication and the willingness to share knowledge. The importance of social capital (trust and tie strength) has been confirmed for academic engagement (Amabile et al. 2001; Philbin 2008; Plewa et al. 2013a; Schartinger et al. 2002).

As can be seen from the previous text, the factors that influence knowledge transfer are interrelated. Trust is positively influenced by tie strength and shared goals, and negatively by ambiguity and organizational differences. Tie strength improves absorptive capacity, as more interaction provides more opportunities to exchange knowledge. Ambiguity can be reduced by tie strength as well. Reduced ambiguity in return improves absorptive capacity and the understanding of the goals and needs of the partner. When there are large differences between organizational cultures, it is more likely that organizations have different research goals and possibly also different knowledge backgrounds. This can result in more ambiguity and less trust in that the partner will do what is right for you.

\section{Results}

In the following part we will discuss the findings from the literature we reviewed. For each of the three topics we identified we will discuss the theoretical insights, their implications and the associated practices for successful knowledge transfer.

\subsection{Cognitive differences}

We start with a general discussion on knowledge flows in academic engagement. After this, we turn to theoretical insights about how knowledge differences and characteristics influence the effectiveness of knowledge exchange and absorptive capacity. Finally, we discuss how different practices of knowledge exchange are influenced by these factors and which practices help to improve knowledge transfer from a cognitive differences perspective.

Looking at the papers in our review, the overall picture is that the extant literature pays little attention to the knowledge contribution of industrial partners. The majority of 
the papers focuses on development and transfer of knowledge by the academic partner. The knowledge contribution from the industrial partner is reduced to formulating interesting research problems (D'Este and Perkmann 2011; McCabe et al. 2016) and providing data and insight in the application context (Barnes et al. 2002; Gertner et al. 2011; Hadjimanolis 2006; McCabe et al. 2016; Wang and Lu 2007).

Ulhøi et al. (2012) focus specifically at the knowledge contribution of the industrial partner. They sketch a much more dynamic exchange process, in which the industrial application of research outcomes directly influences academic research. This discrepancy is partly explained by McCabe et al. (2016) who discusses three levels of collaboration, low, high and deep, and links them to different knowledge exchange practices. In collaborations with low engagement the firm is seen as data source, while all research activities are controlled and conducted by the academic partner. In high collaborations the firm contributes through the identification of research problems, grounding the design and data collection in the application context and by assisting academics in making decisions. In ideal circumstances during deep collaboration the industrial partner would take a more equal role as the academics and contribute to the identification of research problems, help with the selection of methods and is engaged in data gathering and analysis. In practice, the role of the industrial partner in data analysis and theory development is limited, even in deep collaborations. Because industrial partners lack the time to dive into the data and feel unequipped to participate truly in the academic debate (McCabe et al. 2016). Also, academics hardly use data that is produced by the industrial partner due to a lack of quality signals of industrial data that is required for academic publication (Canhoto et al. 2016). Additionally, academic knowledge and expertise is valued higher than industrial knowledge. This makes industrial partners reluctant to take part in the research and the academic debate (McCabe et al. 2016).

The ease with which knowledge is transferred depends on the characteristics of knowledge, similarities in knowledge background and knowledge management capabilities. We will discuss each of these aspects in the following paragraphs.

The most important characteristic of knowledge is its explicitness (Santoro and Bierly 2006). Knowledge that can be made explicit can be transferred through prototypes, formulas or manuals. Such knowledge is often transferred through contractual agreements, like patents (Alexander and Childe 2013; Sandberg et al. 2015). In that case the successful use of the knowledge depends on whether it can be appropriated to the application contexts (Alexander and Childe 2013; Sandberg et al. 2015; Wang and Lu 2007). Tacit knowledge transfer requires interaction to develop competence (Johnson and Johnston 2004) and more direct collaboration (Alexander and Childe 2013; Azevedo Ferreira and Rezende Ramos 2015; Daghfous 2004; Gertner et al. 2011; Steinmo 2015; Wang and Lu 2007) and interactional expertise (Canhoto et al. 2016; Sandberg et al. 2015). Therefore, tacit knowledge is best transferred through academic engagement, instead of patenting or licensing, as it includes more personal interaction.

Nonaka (1994) developed the knowledge creation circle to explain tacit knowledge transfer. Which shows that tacit knowledge is transferred in four steps; (1) through creating shared experiences (socialization), after which knowledge is (2) externalized, (3) recombined and (4) internalized. Johnson and Johnston (2004) explored how the knowledge creation cycle affects knowledge transfer in academic engagement. They found that all four steps of the knowledge creation cycle (socialization, externalization, combination and internalization) were needed in the initiation phase, to formulate relevant research questions and goals, and in the knowledge transfer phase, to absorb tacit 
knowledge. The need to go through the whole knowledge cycle in both phases distinguishes collaborative research from other learning processes.

The second important factor that influences knowledge absorption, is differences in knowledge background, referred to as cognitive and epistemic difference. They result in differences in 'language' and different logics regarding what methods should be used. Therefore, relatedness of prior knowledge and technological competence help to understand and integrate new knowledge (Daghfous 2004; Santoro and Bierly 2006) and reduces ambiguity.

Although cognitive distance does not diminish the propensity to collaborate, it does limit interaction during the collaboration. Resultantly, tacit knowledge transfer which requires interaction is limited. But is might also be problematic for forms of engagement that require interaction relating to the use of methods and technology, like joint research or sharing facilities (Sandberg et al. 2015).

Studies on prior knowledge have asked how prior technological knowledge and management capabilities are related. There seems to be agreement on the importance of general collaboration experience, organizational capabilities, and experience with the particular partners for overall collaboration success (Buganza et al. 2014; Bjerregaard 2009; Canhoto et al. 2016; Daghfous 2004; Sandberg et al. 2015). Studies that particularly studied cognitive difference in relation to knowledge transfer are contradictory about the effect of experience. Daghfous's (2004) and Muscio and Pozzali (2013) found that cognitive differences are not diminished by experience. To which Daghfous's (2004) adds that systematic learning in relation to management skills does not significantly increase learning capabilities. Steinmo (2015), on the other hand, found that cognitive capital can be developed over time at the organizational level. While research by (Corley et al. 2006) indicates that epistemic differences can be reduced by strong organizational routines. Therefore, the role of experience to mitigate knowledge differences remains unclear. If experience or management capabilities do not reduce cognitive differences, identifying suitable partners with matching knowledge backgrounds is an important success factor (Galan-Muros and Plewa 2016). Finding the right partners is especially difficult for SME (small and medium size enterprises) as they have smaller networks (Buganza et al. 2014).

The relevance of technical and organizational uncertainties in relation to learning activities is unclear as well. A study by Daghfous (2004) indicated that prior knowledge was only significant in case of high uncertainty about the organizational aspects for the implementation of the new knowledge. His hypotheses is that in the case of radically new technologies knowledge is so different from existing knowledge that knowing how to organize the implementation of new technologies becomes more relevant. This needs to be confirmed by future research.

We now turn to practices that can improve knowledge transfer. Communication is an important facilitator to improve absorptive capacity. The channels for communication during engagement are diverse and differ in their ability to transfer tacit knowledge and to deal with differences in knowledge backgrounds (Alexander and Childe 2013). Knowledge transfer through rich, or interactive, media is preferred over indirect communication through reports, presentations, patents and so forth, as the latter are unable to transfer tacit knowledge (Alexander and Childe 2013; Sandberg et al. 2015).

We noticed that three reoccurring practices are important for rich communication practices: boundary spanners (Al-Tabbaa and Ankrah 2016; Barnes et al. 2002; Gertner et al. 2011, Hadjimanolis 2006; Wallin et al. 2014), training (Alexander and Childe 2013; Azevedo Ferreira and Rezende Ramos 2015; Daghfous 2004; Gertner et al. 2011; Wallin et al. 2014; Wang and Lu 2007) and the use of tools or objects (Buganza et al. 2014; Wallin 
et al. 2014). We will continue with discussing how each of these practices can be used effectively to transfer knowledge according to the literature.

Boundary spanners are often personnel that is exchanged between academia and industry during the course of the collaboration. For instance, the outplacement of personnel from the firm, secondment and employment of graduates (Galan-Muros and Plewa 2016; Gertner et al. 2011; Harryson et al. 2007; Hadjimanolis 2006; Pinheiro et al. 2015; Ulhøi et al. 2012; Wang and Lu 2007) or (Ph.D.) students that do part of their research at the firm (Gertner et al. 2011; Galan-Muros and Plewa 2016; Hadjimanolis 2006; Harryson et al. 2007; Wang and Lu 2007). Such mobility can be limited by organizational differences (Galan-Muros and Plewa 2016).

If partners mainly interact through periodical meetings instead of personnel exchange the identification of suitable recipients within the firm, who have the right knowledge background is essential. This requires time and commitment (Mesny and Mailhot 2007; Plewa et al. 2013a).

Boundary spanners are effective because they facilitate the knowledge conversion and translation of academics results to the context of the firm and vice versa (Azevedo Ferreira and Rezende Ramos 2015; Gertner et al. 2011). This requires the investment of time to develop a shared language and discourse (Al-Tabbaa and Ankrah 2016; Canhoto et al. 2016). Over time and through close collaboration the boundary spanner gets a better understanding of the partner's needs and knowledge background. This enables him to translate results which facilitate application and implementation (Gertner et al. 2011; Hadjimanolis 2006; Wang and $\mathrm{Lu}$ 2007). Firm employees who interact frequently with researchers and follow the debate at academic meetings gain a deeper understanding of the working methods and knowledge produced by the researchers. This helps to integrate the results of the research (McCabe et al. 2016).

Training and workshops help to transfer tacit, complex knowledge and build skills (Azevedo Ferreira and Rezende Ramos 2015; Daghfous 2004). They provide a space for deliberation and feedback which increases the comprehension of results (McCabe et al. 2016). It is important to have the right people, with the right level of expertise, involved in these meetings (Azevedo Ferreira and Rezende Ramos 2015). The open and interactive mode of communication in this kind of meetings gives industrial partners the possibility to engage more and feel more comfortable about giving input (McCabe et al. 2016). Creating creative chaos in interactive sessions provides a way to learn autonomic and recombine the new insights with previous knowledge, which facilitates absorption (Johnson and Johnston 2004).

The use of prototypes and working in the facilities of the industrial partner helps to integrate knowledge and learn about implementation challenges (Daghfous 2004; Gertner et al. 2011; Hadjimanolis 2006; Wallin et al. 2014; Wang and Lu 2007). Mostly because it helps to see connections between different aspects of knowledge and this is an important way to reduce ambiguity. Close interaction is also the most important way for researchers to identify interesting questions for future research (Perkmann and Walsh 2007; Ulhøi et al. 2012; Wang and Lu 2007).

\subsection{Institutional differences}

Differences in organizational goals and culture are a frequently mentioned, but not well defined barrier to academic engagement. The literature we reviewed uses the term cultural differences to indicate differences in project goals, expected outcomes, visions on required 
research activities, the allocation of time and resources, management styles, social conducts, cognitive differences, different 'language' and time perception (Bjerregaard 2010; Galan-Muros and Plewa 2016; Ghauri and Rosendo-Rios 2016; Harryson et al. 2007). In spite of that, they are frequently mentioned as barrier, they are not well researched. It is therefore much welcomed, that since 2013 more research has been conducted into how institutional differences influence knowledge transfer and collaboration success.

There remains discussion about the extent to which cultural differences actually affect collaboration in practice. On the one hand, it has been shown that increasing academic convergence between companies and industry reduce the differences (Bjerregaard 2010). On the other hand, the limited statistical research on cultural differences indicates that cultural differences do affect collaboration success (Galan-Muros and Plewa 2016; Ghauri and Rosendo-Rios 2016). Ghauri and Rosendo-Rios (2016) found that especially market and time orientation affect collaboration success.

Differences in goals originate from differences in market orientation (Ghauri and Rosendo-Rios 2016), priorities in norms (Al-Tabbaa and Ankrah 2016; Mesny and Mailhot 2007), and different logics for the sharing of knowledge (Steinmo 2015). Differences in goals are best managed by improved communication (Bjerregaard 2009; Plewa et al. 2013b). Goals and outcomes should be established early in the project. The use of project plans that outline goals and outcomes could facilitate this (Canhoto et al. 2016; Morandi 2013). Project management tools can be helpful in the communication of progress and the relation between goals and outcomes (Wallin et al. 2014). A complicating factor here is that differences in goals are often not recognized in the early, 'honeymoon', stage of a collaboration, they become clear during the engagement phase (Estrada et al. 2016; Plewa et al. 2013a). In this phase the selection of actual research questions, methods and resource allocation might provide problems, even if these matters seemed clear at the beginning (Estrada et al. 2016; Mesny and Mailhot 2007; Plewa et al. 2013a).

Researchers are expected to put sufficient effort into understanding the needs of the industrial partner; this becomes especially important during the engagement phase (Canhoto et al. 2016; Ghauri and Rosendo-Rios 2016; Plewa et al. 2013a). Expectation management about what can be achieved in the available time and when results can be expected is also important to keep industrial partners satisfied (Azevedo Ferreira and Rezende Ramos 2015; Barnes et al. 2002; Bjerregaard 2009; Sandberg et al. 2015; Steinmo 2015; Wallin et al. 2014).

Frequent meetings and deliberation are key to recognize and solve differences (Morandi 2013; Plewa et al. 2013b; Steinmo 2015). The possibility for interactive discussion for the coordination of goals is important to keep industrial and academic expectations aligned (Johnson and Johnston 2004). Experience with the collaboration partner has been found to mitigate problems relating to differences in goals, because it leads to more realistic expectations and better insight in the partner's needs (Azevedo Ferreira and Rezende Ramos 2015; Steinmo 2015; Wallin et al. 2014). Finally, looking for a higher common good can help to re-unite goals if there seems to be no common ground (Mesny and Mailhot 2007).

A highly valued academic norm is academic freedom, the autonomy to follow interesting directions and choose one's own research problems and methods. This may conflict with making strict project plans and specifying deliverables that align with industrial needs. A good understanding of a partner's needs helps to take these needs into account, also when novel directions are pursued, while open communication raises understanding. Zhu and Hawk (2015) show how academics at Stanford University and MIT (Michigan Institute for Technology) managed to maintain their academic freedom. They focus on fundamental research, but use market developments to inspire their research. This way they 
manage to secure industrial funding. At the same time strict conflict of interest policies are in place to prevent conflicts of interests.

Cultural differences that are referred to as institutional norms or organizational routines relate to differences in project management and time orientation. Time orientation relates to differences in what is considered an acceptable period to reach goals, punctuality in meeting deadlines and the continuity of personnel (Barnes et al. 2002; Ghauri and Rosendo-Rios 2016). The industrial partner's aversion to long term orientation of academics and the fundamental nature of research can be managed by open communication and good project management. This requires clarifying communication channels, providing and updating project plans and punctuality from academics (Barnes et al. 2002; Ghauri and Rosendo-Rios 2016; Morandi 2013; Wallin et al. 2014). Estrada et al. (2016) found that such 'routine' based differences, meaning dissimilarities in working methods, could only be resolved when orientation based differences, meaning dissimilarities in goals, were settled.

Cultural differences relating to the application of knowledge and willingness to share knowledge relates to the academic habit to publish results, while industrial partners rather keep knowledge secret. These differences can be handled through publication management and upfront arrangement of IP (intellectual property) rights (Azevedo Ferreira and Rezende Ramos 2015). However, arranging IP too early in the collaboration might negatively influence trust between partners (Canhoto et al. 2016). Publication management includes arrangements regarding what data can be published and allows the industrial partner to authorize publication, this ensure academics do not publish sensitive knowledge (Azevedo Ferreira and Rezende Ramos 2015). Also, providing the industrial partner the possibility to delay the publication to arrange IP rights reduces this barrier (Hadjimanolis 2006).

\subsection{Social capital}

Trust has been shown to influence knowledge transfer in research partnerships (Bruneel et al. 2010; Plewa et al. 2013b; Ulhøi et al. 2012). Mostly, because it reduces fear of opportunistic behaviour and, resultantly, increases the willingness to share information (Plewa et al. 2013b; Philbin 2008; Sherwood and Covin 2008; Steinmo 2015). Trust increases with frequent communication. Therefore, tie strength improves trust (Al-Tabbaa and Ankrah 2016; Plewa et al. 2013b).

Trust in U-I collaboration is affected by two things. First, industrial partners fear that the academic partner is not working on the same goals, due to institutional differences, and that academics use the industrial partner as money cow (Al-Tabbaa and Ankrah 2016; Pinheiro et al. 2015; Ulhøi et al. 2012). Second, there is a fear that academic partners, unintentionally, share sensitive knowledge with other companies, due to a lack of experience with handling sensitive knowledge (Ulhøi et al. 2012). The latter can be prevented by providing secrecy training and using a split management strategy. Meaning that academics who work for different companies should not be mixed in research projects (Ulhøi et al. 2012). Fear for a lack of common interests is reduced by building social capital, which includes, tie-strength, and collaboration experience with the particular partner (Pinheiro et al. 2015; Sandberg et al. 2015). Frequent meetings in the initiation stage also help to merge goals, keep them aligned and increase trust (Plewa et al. 2013b).

What is needed to build trust also depends on the collaboration stage. In the initiation stage trust is mainly based on the reputation of and previous experiences with the partner (Plewa et al. 2013b). Resultantly, academic reputation and previous personal ties 
are important drivers for establishing collaborations (Pinheiro et al. 2015; Sandberg et al. 2015). While Muscio and Pozzali (2013) found that research quality is less important for establishing the collaboration than the applicability, in the sense of 'readiness to use', of the knowledge that will be produced.

During the collaboration the quality of communication is important. Social capital is built through frequent face-to-face communication and workshops that facilitate interaction (Al-Tabbaa and Ankrah 2016; Plewa et al. 2013b). This kind of communication improves insight in the partner's goals. Spontaneously sharing interesting knowledge that is not directly related to the specific project, experience and successful previous collaborations make partners feel that the other is genuinely interested in what is needed and improves insight in the partner's needs (Al-Tabbaa and Ankrah 2016; Pinheiro et al. 2015). Therefore, it is often recommended to start with small projects, like student projects, and build to more complex collaborations and more fundamental questions from there (Buganza et al. 2014; Pinheiro et al. 2015). This way managerial capabilities can be developed and academic work can be aligned with business challenges (Buganza et al. 2014; Plewa et al. 2013a; Pinheiro et al. 2015).

Trust also influences the contractual and organizational management of the collaboration. Trust results in less formal contractual agreements (Chin et al. 2011; Morandi 2013; Ulhøi et al. 2012). When there are no IP-rights expected the collaboration is often formed by memoires of understanding (MoU) or standard documents from the technology transfer office (TTO) instead of legal contracts (ibid). Additionally, trust is reflected in the absence of formal control mechanisms. Coordination is often effected informally between project managers from both sides (Barnes et al. 2002; Chin et al. 2011; Morandi 2013). This can lead to confusion when university partners have several senior researchers, and it is unclear who is in control (Barnes et al. 2002). Appointing a single person from both organizations as a liaison has therefore been recommended (Morandi 2013).

Furthermore, trust influences the formalization of communication. Regular contact during the collaboration is important to ensure that goals remain aligned (Buganza et al. 2014; Plewa et al. 2013a). To align goals, projects often start with a project plan, which allocates tasks and responsibilities and milestones in detail (Barnes et al. 2002; Morandi 2013). These plans are rarely updated as the work develops and they soon become obsolete. The risk in this kind of work is that projects deviate from original plans, or that changes in plans are not well administrated and lead to discussion later on. Collaborations involving mutually dependent research form an exceptions, these plans are more likely to be updated to coordinate activities (Morandi 2013).

Although partners expect to be informed, reports play a minor role in this and are usually only compiled at the end of each phase and perceived as archiving material (Chin et al. 2011; Morandi 2013). Preferably, results are discussed in informal settings and regular progress meetings, or informally by email (discussions) and telephone (Chin et al. 2011; Morandi 2013; Ulhøi et al. 2012).

\section{Conclusion}

This review aimed to explore the relevance of knowledge transfer as a concept for theory development regarding academic engagement and to give an overview of literature that addresses knowledge transfer in academic engagement. We found that research into knowledge transfer in academic engagement is dispersed. This could be due to incoherence in 
terminology at all levels; from terminology to indicate the form of engagement to the factors and theoretical frames that are used to discuss knowledge transfer.

Nevertheless, knowledge transfer seems an interesting perspective for theory development for research into academic engagement. Our framework and the factors found by van Wijk et al. (2008) provided an interesting starting point for a more focused analysis, and integration of concepts. We also found that especially qualitative research can benefit from a better theoretical bedding for its analysis in order to provide better funded insights in the mechanisms behind success and fail factors of academic engagement. And makes it easier to build on previous research.

Bringing together this literature on knowledge transfer enabled us to develop a stylised model that shows how different characteristics of knowledge transfer relate in the context of academic engagement (Fig. 3). We could also compare previous research outcomes and draw new conclusions by connecting empirical results with theoretical explanations and by identifying dissimilarities that require more research. In the remainder of this paper we present the stylised model and the implications of our analysis for future research and management.

We found two promising lines of research. The first, deals with the cognitive differences and the adsorption of knowledge. The second, with differences in goals and the applicability of knowledge. We also identified the most relevant factors and practices for the mitigation of these differences. Trust and communication help to overcome both, cognitive differences and differences in goals. Intermediaries mainly help to reduce cognitive differences, and experience primarily helps to resolve differences is goals.

In relation to cognitive differences there seems to be agreement that secondment, employee exchange and hiring graduates are important ways to (bi-directionally) transfer the tacit aspects of knowledge and that Master and $\mathrm{PhD}$ students can play a particularly important role in this (Gertner et al. 2011; Harryson et al. 2007; Thune 2009). Because similarity in knowledge background is so important for absorptive capacity, we recommend that this is taken into account in partner selection. The use of prototypes and models helps to resolve ambiguity and to connect new and extant knowledge. For absorptive capacity, trust is foremost a mediating factor, because it increases the willingness to share knowledge. Communication practices on the other hand are very important for the quality of knowledge sharing. Communication should be open, interactive and bidirectional, for

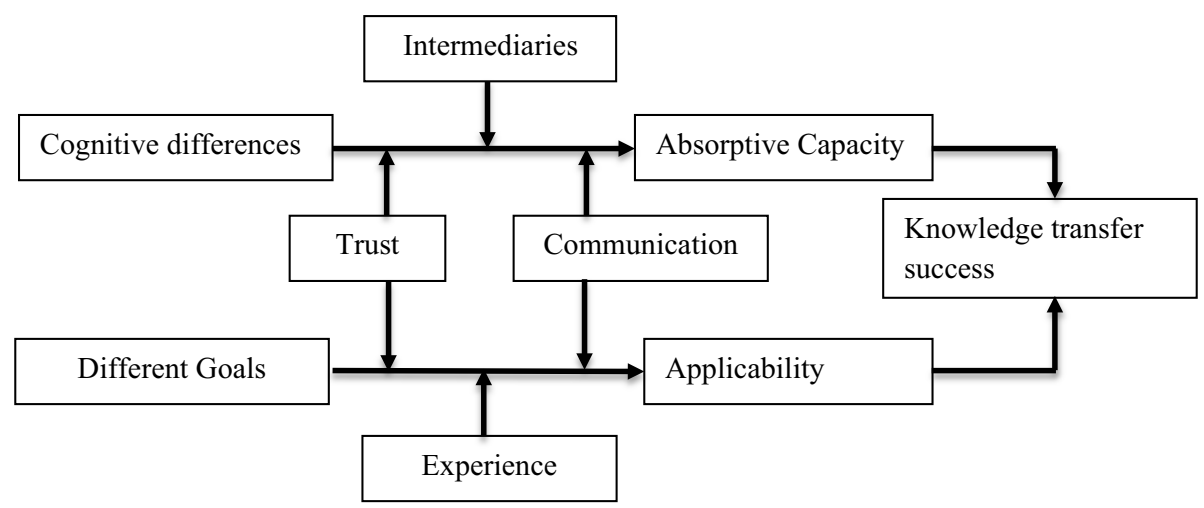

Fig. 3 Analytical framework of knowledge transfer success in academic engagement 
instance in the form of workshops, to recognize and resolve cognitive differences. When tacit knowledge needs to be transferred this requires on the job training or the hiring of graduates who worked on the project. The use of prototypes to show underlying relations can help to manage ambiguity. The role of experience to mitigate differences in knowledge background remains unclear. We believe that experience can help overcome minor differences through learning activities, but does not resolve fundamental differences in epistemic background or knowledge background without extensive learning. For example, an ICTprofessional will not learn fundamental physics through collaboration experience; this requires extensive training.

The second line of research, applicability of knowledge, is highly dependent on goal similarity of the partners. Industrial partners often feel (or fear) that differences in knowledge application requirements might go at the costs of industrial needs if there is too much focus on academic relevance and publication requirements. While the need to publish might be at odds with the need to protect sensitive company knowledge and hamper trust. Communication to determine goals and to discuss what information can be published is the most important way to deal with these differences. Drawing up project plans that include milestones and the use of management tools can improve trust in the willingness of the academic to take into account industrial needs. Furthermore, experience with academic engagement in general and the specific partner in particular will build understanding for the needs of industry and the particular partner more specifically. Collaboration experience with the specific partner also increases trust in that the partner will handle sensitive information carefully.

\subsection{Future research agenda}

We can identify a number of avenues for future research into knowledge transfer related to academic engagement. These suggestions are based on open questions we encountered during our analysis and inconsistencies between the results in the papers discussed here.

Absorptive capacity, ambiguity and cognitive distance seem to be the most difficult barriers to be resolved. There remains uncertainty over the relevance of experience and management capabilities to solve transfer problems related to knowledge differences. This requires more research. Also, there seems to be agreement that secondment, employee exchange and hiring graduates are important ways to transfer the tacit aspects of knowledge in both directions. However, there is a need for more insight into the firms' perspective on the involvement of students and Ph.D.'s in research partnerships (Thune 2009), as most research discusses the academic perspective only.

We noticed that "cultural differences" is used as an aggregated term for different goals, organizational and managerial differences and epistemic norms. This is problematic as it makes it hard to understand the cause-effect relations of the individual aspects of cultural differences on knowledge transfer. Research that differentiates between cognitive or goal related differences and routine based differences indicates that these factors affect collaborations differently (Corley et al. 2006; Estrada et al. 2016). A more structured approach is required which distinguishes between the effects of single attributes of cultural differences and their effect on collaboration success and knowledge transfer.

The extent to which cultural differences affect academic engagement is unclear, even as the role of experience to reduce this barrier. Bjerregaard (2010) and Bruneel et al. (2010) found that experience and academic convergence reduces differences. While Muscio and Pozzali (2013) and Morandi (2013) found that more experience in interaction with firms does not change the perception of cognitive distance. Firms indicated 
that different logics remained problematic for the development of useful interaction with universities, but that this disadvantage was outweighed by the benefits of the collaboration (Morandi 2013). There seems to be a need for future research to improve our understanding of how cultural differences are managed.

The relation between trust and knowledge transfer and the specific threats perceived in U-I collaborations requires greater attention in future studies (Plewa et al. 2013a, b). We noticed that trust issues for research partnerships differ from those for businessto-business collaborations. Yet the trust scales used most frequently in the papers we reviewed are the ones intended for analysing business-to-business relations, developed by Saparito et al. (2004). Therefore, these do not fully reflect the trust related concerns we encountered in our analysis. Secondly, trust is mainly researched in quantitative research in relation to general collaboration success. Little attention has been paid to the practices required to build trust or the effect of trust on knowledge transfer specifically.

From the papers we studied, it seems that U-I research partnerships are managed informally (e.g. MoU instead of formal contract, informal reporting), or as Powell et al. (1996) call it, irrational. This is in contrast with the findings of Ankrah and AL-Tabbaa (2015), who argue that U-I collaborations are managed as rational process: focusing on planned resource and knowledge transfer. This could be due to a difference in focus, as Ankrah and AL-Tabbaa (2015) focus on negotiations in the pre-collaboration phase and their data included many results related to academic entrepreneurship, while the papers we analysed focus on the execution of the project and research partnerships. Yet, we believe this difference taps into a broader debate, on the governance of university knowledge transfer, presented by Geuna and Muscio (2009), who argue that U-I collaborations have a more informal irrational management style than is often assumed. This is also confirmed by the papers in our review, which show a very informal management style, based on high levels of trust. In our view, an increased understanding of when informal or formal management mechanisms are used is needed.

We also found that the current literature is focussed on the responsibilities and perception of the academic partner, with very limited attention for the role of the industrial partner. While knowledge transfer is a bidirectional process. This could lead to an underestimation of the importance of the firm's efforts to absorb knowledge and communicate its needs to the researcher. More attention for how firms manage research partnerships is therefore needed. On the other hand, it would be interesting to gain greater insight into what knowledge academics require from firms, to enables them to provide relevant results and manage the knowledge needs of the firm. Also, the literature mainly focuses on problems in the implementation phase. There is room left for research into problem management during the initiation and collaboration phase.

Closing the gap between qualitative and quantitative research is another way to bring the field forward. Qualitative and quantitative research has both identified factors which influence knowledge transfer, but have not integrated their results. Such integration would increase the understanding of the underlying mechanisms. Qualitative research in this field is often very descriptive and does not refer to theoretical concepts.

Researchers who consider using results from this paper should be aware of the fact, that the qualitative nature of most research papers we used in this review, the small samples in both case study and quantitative studies we reviewed, and the sample bias of the selected cases in these studies (discussing only one sector, one university or a single research collaboration) might influence the validity of results we discussed. Resultantly, the conclusions we draw about the relation between different factors require more 
research. We therefore invite scholars to conduct more research into the relationships we proposed in our model.

\subsection{Managerial implications}

In our analysis we identified a number of barriers to successful knowledge transfer in academic engagement. We also identified the practices that could help to overcome those barriers. We found that cognitive differences are hard to overcome without the presences of boundary spanners or intermediaries. Therefore, we recommend to carefully select knowledge partners and the persons who represent the company. During the collaboration knowledge is best transferred through rich, meaningful, direct and bilateral interaction, especially when tacit knowledge is involved. Attributing sufficient time for interaction is important to reap the fruits of the partnership. Workplace mobility of employees during and after the collaboration seems the best way to transfer and implement (tacit) knowledge, while these employees also act as intermediaries to align goals.

Collaboration experience with a specific partner and learning how to deal with differences seems the best way to overcome differences in logic and goals. It can be wise to start with smaller projects, such as student internships or thesis research, to gain collaboration experience and to learn about the capabilities of a partner. Drawing up project plans and the use of management tools can help to make differences in goals visible over the course of the project. If they are regularly updated they help to keep goals and research work aligned.

Open Access This article is distributed under the terms of the Creative Commons Attribution 4.0 International License (http://creativecommons.org/licenses/by/4.0/), which permits unrestricted use, distribution, and reproduction in any medium, provided you give appropriate credit to the original author(s) and the source, provide a link to the Creative Commons license, and indicate if changes were made.

\section{References}

Agrawal, A. K. (2001). University-to-industry knowledge transfer: Literature review and unanswered questions. International Journal of Management Reviews, 3(4), 285-302.

Alexander, A. T., \& Childe, S. J. (2013). Innovation: A knowledge transfer perspective. Production Planning and Control, 24(2-3), 208-225.

Al-Tabbaa, O., \& Ankrah, S. (2016). Social capital to facilitate 'engineered' university-industry collaboration for technology transfer: A dynamic perspective. Technological Forecasting and Social Change, 104, 1-15.

Amabile, T. M., Patterson, C., Mueller, J., Wojcik, T., Odomirok, P. W., Marsh, M., et al. (2001). Academic-practitioner collaboration in management research: A case of cross-profession collaboration. Academy of Management Journal, 44(2), 418-431.

Ankrah, S., \& AL-Tabbaa, O. (2015). Universities-industry collaboration: A literature review. Scandinavian Journal of Management, 31(3), 387-408.

Azevedo Ferreira, M. L., \& Rezende Ramos, R. (2015). Making university-industry technological partnerships work: A case study in the Brazilian oil innovation system. Journal of Technology Management and Innovation, 10(1), 173-187.

Barnes, T., Pashby, I., \& Gibbons, A. (2002). Effective university-industry interaction: A multi-case evaluation of collaborative R\&D projects. European Management Journal, 20(3), 272-285.

Bercovitz, J., \& Feldmann, M. (2006). Entrepreneurial universities and technology transfer: A conceptual framework for understanding knowledge-based economic development. The Journal of Technology Transfer, 31(2), 175-188.

Bjerregaard, T. (2009). Universities-industry collaboration strategies: A micro-level perspective. European Journal of Innovation Management, 12(2), 161-176. 
Bjerregaard, T. (2010). Industry and academia in convergence: Micro-institutional dimensions of R\&D collaboration. Technovation, 30(2), 100-108.

Bloedon, R. V., \& Stokes, D. R. (1994). Making university/industry collaborative research succeed. Research Technology Management, 37(2), 44-48.

Bruneel, J., D'Este, P., \& Salter, A. (2010). Investigating the factors that diminish the barriers to universityindustry collaboration. Research Policy, 39(7), 858-868.

Buganza, T., Colombo, G., \& Landoni, P. (2014). Small and medium enterprises' collaborations with universities for new product development: An analysis of the different phases. Journal of Small Business and Enterprise Development, 21(1), 69-86.

Canhoto, A. I., Quinton, S., Jackson, P., \& Dibb, S. (2016). The co-production of value in digital, university-industry R\&D collaborative projects. Industrial Marketing Management, 56, 86-96.

Chin, C. M. M., Yap, E. H., \& Spowage, A. C. (2011). Project management methodology for universityindustry collaborative projects. Review of International Comparative Management/Revista De Management Comparat International, 12(5), 901-918.

Cohen, W. M. (2002). Links and impacts: The influence of public research on industrial R D. Management Science, 48(1), 1-23.

Cohen, W. M., \& Levinthal, D. A. (1990). Absorptive capacity: A new perspective on learning and innovation. Administrative Science Quarterly, 35(1), 128-152.

Corley, E. A., Boardman, P. C., \& Bozeman, B. (2006). Design and the management of multi-institutional research collaborations: Theoretical implications from two case studies. Research Policy, 35(7), 975-993.

Cyert, R. M., \& Goodman, P. S. (1997). Creating effective university-industry alliances: An organizational learning perspective. Organizational Dynamics, 25(4), 45-57.

D'Este, P., \& Perkmann, M. (2011). Why do academics engage with industry? The entrepreneurial university and individual motivations. The Journal of Technology Transfer, 36(3), 316-339.

Daghfous, A. (2004). An empirical investigation of the roles of prior knowledge and learning activities in technology transfer. Technovation, 24(12), 939-953.

Davenport, S., Davies, J., \& Grimes, C. (1998). Collaborative research programmes: Building trust from difference. Technovation, 19(1), 31-40.

Estrada, I., Faems, D., Martin Cruz, N., \& Perez Santana, P. (2016). The role of inter-partner dissimilarities in industry-university alliances: Insights from a comparative case study. Research Policy, 45(10), 2008-2022.

Galan-Muros, V., \& Plewa, C. (2016). What drives and inhibits university-business cooperation in Europe? A comprehensive assessment. $R \& D$ Management, 46(2), 369-382.

Geuna, A., \& Muscio, A. (2009). The governance of university knowledge transfer: A critical review of the literature. Minerva, 47(1), 93-114.

Gertner, D., Roberts, J., \& Charles, D. (2011). University-industry collaboration: A CoPs approach to KTPs. Journal of Knowledge Management, 15(4), 625-647.

Ghauri, P., \& Rosendo-Rios, V. (2016). Organizational cross-cultural differences in the context of innovation-oriented partnerships. Cross Cultural and Strategic Management, 23(1), 128-157.

Hadjimanolis, A. (2006). A case study of SME-university research collaboration in the context of a small peripheral country (Cyprus). International Journal of Innovation Management, 10(1), 65-88.

Hagedoorn, J. (2002). Inter-firm R\&D partnerships: An overview of major trends and patterns since 1960. Research Policy, 31(4), 477-492.

Hagedoorn, J., Link, A. N., \& Vonortas, N. S. (2000). Research partnerships. Research Policy, 29(4), $567-586$.

Hansen, M. T. (1999). The search-transfer problem: The role of weak ties in sharing knowledge across organization subunits. Administrative Science Quarterly, 44(1), 82-111.

Harryson, S., Kliknaité, S., \& Dudkowski, R. (2007). Making innovative use of academic knowledge to enhance corporate technology innovation impact. International Journal of Technology Management, $39(1 / 2), 131-157$.

Inkpen, A. C. (2000). Learning through joint ventures: A framework of knowledge acquisition. Journal of Management Studies, 37(7), 1019-1044.

Johnson, W., \& Johnston, D. (2004). Organisational knowledge creating processes and the performance of university-industry collaborative R\&D projects. International Journal of Technology Management, 27(1), 93-114.

Lane, P. J., \& Lubatkin, M. (1998). Relative absorptive capacity and interorganizational learning. Strategic Management Journal, 19(5), 461-477.

Liyanage, S., \& Mitchell, H. (1994). Strategic management of interactions at the academic-industry interface. Technovation, 14(10), 641-655. 
McCabe, A., Parker, R., \& Cox, S. (2016). The ceiling to coproduction in university-industry research collaboration. Higher Education Research and Development, 35(3), 560-574.

Mesny, A., \& Mailhot, C. (2007). The difficult search for compromises in a Canadian industry/university research partnership. The Canadian Journal of Sociology, 32(2), 203-227.

Morandi, V. (2013). The management of industry-university joint research projects: How do partners coordinate and control R\&D activities? The Journal of Technology Transfer, 38(2), 1-24.

Mowery, D. C., \& Nelson, R. R. (2004). Ivory tower and industrial innovation. Palo Alto: Stanford University Press.

Mowery, D. C., \& Shane, S. (2002). Introduction to the special issue on university entrepreneurship and technology transfer. Management Science, 48(1), 5-89.

Muscio, A., \& Pozzali, A. (2013). The effects of cognitive distance in university-industry collaborations: Some evidence from Italian universities. Journal of Technology Transfer, 38(4), 486-508.

Nicolini, D. (2009). Zooming in and out: Studying practices by switching theoretical lenses and trailing connections. Organization Studies, 30(12), 1391-1418.

Nonaka, I. (1994). A dynamic theory of organizational knowledge creation. Organization Science, 5(1), 14-37.

Ouzzani, M., Hammady, H., Fedorowicz, Z., \& Elmagarmid, A. (2016). Rayyan-A web and mobile app for systematic reviews. Systematic Reviews, 5, 210.

Partha, D., \& David, P. A. (1994). Toward a new economics of science. Research Policy, 23(5), 487-521.

Perkmann, M., King, Z., \& Pavelin, S. (2011). Engaging excellence? effects of faculty quality on university engagement with industry. Research Policy, 40(4), 539-552.

Perkmann, M., Tartari, V., McKelvey, M., Autio, E., Broström, A., D’Este, P., et al. (2013). Academic engagement and commercialisation: A review of the literature on university-industry relations. Research Policy, 42(2), 423-442.

Perkmann, M., \& Walsh, K. (2007). University-industry relationships and open innovation: Towards a research agenda. International Journal of Management Reviews, 9(4), 259-280.

Philbin, S. (2008). Measuring the performance of research collaborations. Measuring Business Excellence, 12(3), 16-23.

Pinheiro, M. L., Pinho, J. C., \& Lucas, C. (2015). The outset of UI R\&D relationships: The specific case of biological sciences. European Journal of Innovation Management, 18(3), 282-306.

Plewa, C., Korff, N., Baaken, T., \& Macpherson, G. (2013a). University-industry linkage evolution: An empirical investigation of relational success factors. $R \& D$ Management, 43(4), 365-380.

Plewa, C., Korff, N., Johnson, C., Macpherson, G., Baaken, T., \& Rampersad, G. C. (2013b). The evolution of university-industry linkages-A framework. Journal of Engineering and Technology Management, 30(1), 21-44.

Polanyi, M. (1966). The logic of tacit inference. Philosophy, 41(155), 1-18.

Powell, W. W., Koput, K. W., \& Smith-Doerr, L. (1996). Interorganizational collaboration and the locus of innovation: Networks of learning in biotechnology. Administrative Science Quarterly, 41(1), $116-145$.

Salter, A. J., \& Martin, B. R. (2001). The economic benefits of publicly funded basic research: A critical review. Research Policy, 30(3), 509-532.

Sandberg, J., Holmström, J., Napier, N., \& Levén, P. (2015). Balancing diversity in innovation networks: Trading zones in university-industry R\&D collaboration. European Journal of Innovation Management, 18(1), 44-69.

Santoro, M. D., \& Bierly, P. E. (2006). Facilitators of knowledge transfer in university-industry collaborations: A knowledge-based perspective. IEEE Transactions On Engineering Management, 53(4), 495-507.

Santoro, M. D., \& Gopalakrishnan, S. (2001). Relationship dynamics between university research centres and industrial firms: Their impact on technology transfer activities. The Journal of Technology Transfer, 26(1-2), 163-171.

Saparito, P. A., Chen, C. C., \& Sapienza, H. J. (2004). The role of relational trust in bank-small firm relationships. Academy of Management Journal, 47(3), 400-410.

Schartinger, D., Rammer, C., Fischer, M. M., \& Fröhlich, J. (2002). Knowledge interactions between universities and industry in Austria: Sectoral patterns and determinants. Research Policy, 31(3), 303-328.

Shane, S. (2005). In S. Shane (Ed.), Economic development through entrepreneurship: Government, university and business linkages. Cheltenham: Edward Elgar.

Sherwood, A. L., \& Covin, J. G. (2008). Knowledge acquisition in University-Industry alliances: An empirical investigation from a learning theory perspective. Journal of Product Innovation Management, 25(2), 162-179. 
Simonin, B. (1999). Ambiguity and the process of knowledge transfer in strategic alliances. Strategic Management Journal, 20(7), 595-623.

Steinmo, M. (2015). Collaboration for innovation: A case study on how social capital mitigates collaborative challenges in university-industry research alliances. Industry and Innovation, 22(7), 597-624.

Thune, T. (2009). Doctoral students on the university-industry interface: A review of the literature. Higher Education, 58(5), 637-651.

Tranfield, D., Denyer, D., \& Smart, P. (2003). Towards a methodology for developing evidence-informed management knowledge by means of systematic review. British Journal of Management, 14(3), 207-222.

Tsai, W., \& Ghoshal, S. (1998). Social capital and value creation: The role of intrafirm networks. Academy of Management Journal, 41(4), 464-476.

Ulhøi, J., Neergaard, H., \& Bjerregaard, T. (2012). Beyond unidirectional knowledge transfer: An empirical study of trust-based university-industry research and technology collaboration. International Journal of Entrepreneurship and Innovation, 13(4), 287-299.

Van Wijk, R., Jansen, J. J. P., \& Lyles, M. A. (2008). Inter- and intra-organizational knowledge transfer: A meta-analytic review and assessment of its antecedents and consequences. Journal of Management Studies, 45(4), 830-853.

Wallin, J., Isaksson, O., Larsson, A., \& Elfström, B. (2014). Bridging the gap between university and industry: Three mechanisms for innovation efficiency. International Journal of Innovation and Technology Management, 11(01), 140005.

Wang, Y., \& Lu, L. (2007). Knowledge transfer through effective university-industry interactions: Empirical experiences from china. Journal of Technology Management in China, 2(2), 119-133.

Zhu, F., \& Hawk, S. (2015). Rethinking the relationship between academia and industry: Qualitative case studies of MIT and Stanford. Science and Engineering Ethics, 22(5), 1497-1511. 